\title{
Cidades na pandemia - São Paulo e Rio de Janeiro: comunicação, sociabilidade, vigilância e cidadania
}

\author{
Pandemic cities - São Paulo and Rio de Janeiro: communication, \\ sociability, surveillance and citizenship
}

\section{Ciudades pandémicas - São Paulo y Rio de Janeiro: comunicación, sociabilidad, vigilancia y ciudadanía}

\author{
Raquel Paiva ${ }^{1, a}$ \\ paivaraquel@hotmail.com | https://orcid.org/0000-0001-8786-751X \\ Gisela Grangeiro da Silva Castro ${ }^{2, b}$ \\ castro.gisela@gmail.com | https://orcid.org/0000-0003-0662-3770 \\ Adriana Lima de Oliveira ${ }^{2, c}$ \\ publicidade.dri@gmail.com | https://orcid.org/0000-0003-3731-0611
}

\footnotetext{
${ }^{1}$ Universidade Federal do Rio de Janeiro, Escola de Comunicação, Laboratório de Estudos em Comunicação Comunitária. Rio de Janeiro, RJ, Brasil.

2 Escola Superior de Propaganda e Marketing, Programa de Pós-Graduação em Comunicação e Práticas de Consumo. São Paulo, SP, Brasil.

${ }^{\text {a }}$ Doutorado em Comunicação pela Universidade Federal do Rio de Janeiro.

${ }^{\text {b }}$ Doutorado em Comunicação e Cultura pela Universidade Federal do Rio de Janeiro.

c Mestrado em Comunicação e Práticas de Consumo pela Escola Superior de Propaganda e Marketing.
}

\section{RESUMO}

Dialogando com reflexão de Canclini na quarentena da Cidade do México em 2009 pela epidemia de H1N1, nosso artigo aborda as cidades de São Paulo e Rio de Janeiro para discutir desdobramentos da pandemia da Covid-19. O agravamento da crise denuncia e expõe as flagrantes desigualdades sociais fomentadas pelo modelo de gestão dos espaços urbanos que associa o político ao econômico, favorecendo a concentração de renda e limitando o acesso a recursos de toda ordem. Comunicação, vigilância, sociabilidade e cidadania são os eixos temáticos da discussão apresentada. Ao final, argumentamos sobre a urgência em constituirmos um revigorado horizonte comum de debate e ação coletiva unindo o político ao social.

Palavras-chave: Cidade; Pandemia; Comunicação; Sociabilidade; Cidadania. 


\section{ABSTRACT}

In dialogue with Canclini's reflection during the quarantine of Mexico City in 2009 due to the H1N1 epidemic, our article focuses on the cities of São Paulo and Rio de Janeiro to discuss the unfolding of the Covid-19 pandemic. The worsening of the crisis denounces and exposes the flagrant social inequalities fostered by the current model of management of urban spaces that associates the political with the economic, favoring the concentration of income and limiting access to all kinds of resources. Communication, surveillance, sociability, and citizenship are interwoven in this discussion. In the end, we argue about the urgency of creating an invigorated common horizon of debate and collective action by uniting the political and the social spheres.

Keywords: City; Pandemic; Communication; Sociability; Citizenship.

\section{RESUMEN}

En diálogo con la reflexión de Canclini en la cuarentena de la Ciudad de México en 2009 debido a la epidemia de H1N1, nuestro artículo se centra en las ciudades de São Paulo y Rio de Janeiro para discutir los desarrollos de la pandemia de Covid-19. El agravamiento de la crisis denuncia y expone las flagrantes desigualdades sociales fomentadas por el modelo actual de gestión de espacios urbanos que asocia lo político con lo económico, favoreciendo la concentración de ingresos y limitando el acceso a todo tipo de recursos. Comunicación, vigilancia, sociabilidad y ciudadanía se entrelazan en esta discusión. Al final, discutimos sobre la urgencia de crear un vigorizado horizonte común de debate y acción colectiva uniendo lo político y lo social.

Palabras clave: Ciudad; Pandemia; Comunicación; Sociabilidad; Ciudadanía.

Este artigo compõe o Dossiê Comunicação, Saúde e Crises Globais.

Contribuição dos autores:

Concepção e desenho do estudo: Gisela Grangeiro da Silva Castro e Adriana Lima de Oliveira.

Aquisição, análise ou interpretação dos dados: Raquel Paiva, Gisela Grangeiro da Silva Castro e Adriana Lima de Oliveira.

Redação do manuscrito: Raquel Paiva, Gisela Grangeiro da Silva Castro e Adriana Lima de Oliveira.

Revisão crítica do conteúdo intelectual: Raquel Paiva, Gisela Grangeiro da Silva Castro e Adriana Lima de Oliveira.

Declaração de conflito de interesses: não há.

Fontes de financiamento: não houve.

Considerações éticas: não há.

Agradecimentos/Contribuições adicionais: não há.

Histórico do artigo: submetido: 17 jun. 2020 | aceito: 4 out. 2020 | publicado: 17 dez. 2020.

Apresentação anterior: não há.

Licença CC BY-NC atribuição não comercial. Com essa licença é permitido acessar, baixar (download), copiar, imprimir, compartilhar, reutilizar e distribuir os artigos, desde que para uso não comercial e com a citação da fonte, conferindo os devidos créditos de autoria e menção à Reciis. Nesses casos, nenhuma permissão é necessária por parte dos autores ou dos editores. 


\section{INTRODUÇÃO}

Na quarentena da Cidade do México em meio à epidemia da H1N1 em 2009, Néstor García Canclini ${ }^{1}$ propôs uma reflexão a respeito das práticas culturais entre diferentes grupos de jovens mexicanos, chamando a atenção para a necessidade de se repensar a oferta de conteúdo dos meios de comunicação, bem como a urgência de se combater a exclusão digital dos menos favorecidos. Naquele momento, o autor argumentava ainda que, apesar de nunca termos tido tantas possibilidades de nos comunicarmos remotamente e a despeito da oferta cultural em domicílio por diversos canais, o fechamento de escolas, teatros, cinemas, restaurantes e praças teria demonstrado nossa estreita ligação com o espaço urbano, que também deve ser entendido como local de sociabilidade e afeto.

Onze anos depois, a pandemia da Covid-19 provocou quarentena em escala mundial. Apesar das colossais dessemelhanças entre países, culturas e governos, de uma hora para outra o cotidiano foi radicalmente alterado nas mais diversas cidades. Não demorou muito para que inauditas imagens de parques, monumentos, pontos turísticos e ruas desertas se tornassem rotineiras, denunciando a nova normalidade que inexoravelmente se impõe.

No presente artigo, tomamos como ponto de partida as provocações de Canclini ${ }^{1,2}$ para voltarmos nossa mirada reflexiva em direção às cidades do Rio de Janeiro e São Paulo de modo a tecermos considerações sobre estruturas de sentido que emergem durante a quarentena do novo coronavírus. Pretendemos tratar de entrelaçamentos envolvendo temáticas da comunicação, sociabilidade, vigilância e cidadania na intenção de contribuir para o debate sobre os tempos excepcionais que estamos vivendo.

\section{COMUNICAÇÃO, ACESSO E SOCIABILIDADE NO ESPAÇO URBANO}

A pandemia trouxe uma nova configuração para as cidades no mundo todo. O cenário de isolamento social que atinge ao menos um terço da população mundiali ocasionou medidas extremas tais como o fechamento de comércio e serviços não essenciais. Restrições de circulação impostas por determinações governamentais deixaram ruas e praças vazias. Comoventes reportagens em veículos de grande circulação mostram as principais metrópoles ao redor do mundo praticamente desertas. Contudo, tais imagens insólitas largamente distribuídas pelas redes sociais on-line mascaram outra realidade tornada invisível justamente por nunca ter merecido o foco da atenção: no instante em que a cidade se esvazia, aparece a população que tem na rua o seu espaço de sustento e moradia. Medidas como lavar as mãos, ficar em casa ou trabalhar em regime de home office perdem o sentido quando falta o básico a esses cidadãos socialmente excluídos.

Para a necessária meticulosa higiene, primeiro é preciso ter acesso a água limpa e encanada. Estudos com base no Sistema Nacional de Informação sobre Saneamento ${ }^{3}$ e no Instituto Trata Brasil ${ }^{4}$ mostram que avanços são insuficientes para o País cumprir compromissos nacionais e internacionais em termos de água tratada, coleta e tratamento dos esgotos. No Brasil, 16,38\% da população não têm acesso ao abastecimento de água; 46,85\% não dispõem da cobertura de coleta de esgoto. O desafio se torna ainda maior quando verificamos que somente $46 \%$ do volume de esgoto é tratado. Sem contar que, para ficar em casa, é preciso ter moradia, o que não é uma realidade para $24.344^{\mathrm{ii}, i i i}$ pessoas que vivem em situação de rua, de acordo com dados da gestão municipal da maior cidade brasileira relativos ao ano de 2019. Parte dessa população

\footnotetext{
i Polato A, Macedo L, Modelli L. Um terço da população mundial está em isolamento; veja medidas de diferentes países para conter o coronavirus... G1 [Internet] 2020 mar. 20 [citado em 21 abr. 2020];Bem Estar:Coronavirus. Disponível em: https://g1.globo. com/bemestar/coronavirus/noticia/2020/03/27/13-da-populacao-mundial-esta-em-isolamento-veja-medidas-de-diferentes-paisespara-conter-o-coronavirus.ghtml.

ii Sant' Anna E. São Paulo tem 7.000 pessoas vulneráveis ao coronavírus morando nas ruas... Folha de S.Paulo [Internet]. 2020 mar. 12 [citado em 20202 abr. 21];Cotidiano:Coronavírus. Disponível em: https://bit.ly/2RsSmig.

iii Pauluze T. Recenseadores contestam números do censo de moradores de rua divulgado pela gestão Covas... Folha de S.Paulo [Internet]. 2020 jan. 31[citado em 2020 abr. 21];Cotidiano. Disponível em: https://bit.ly/2yLZeBK.
} 
dorme em albergues - idosos entre eles - e o restante encontra-se exposto às intempéries e, consequentemente, também ao vírus. A situação só deve piorar com a chegada do inverno.

Outra circunstância não menos dramática diz respeito às condições de habitação nas grandes cidades brasileiras: são aproximadamente 13 milhões de pessoas vivendo em favelasiv. Segundo o coordenador da rede de ação coletiva BrCidades, os impactos da pandemia do Covid-19 nesses espaços são ainda imprevisíveis. E finalmente, o que dizer da falta de opção de renda para a maioria dos que estão desempregados ou na informalidade? Dados do Instituto Brasileiro de Geografia e Estatística (IBGE) 5 relativos ao primeiro trimestre de 2020 mostram que o número de desempregados chegou a 12,8 milhões. Aproximadamente 32 milhões de brasileiros são classificados como trabalhadores informais. Sabe-se que esse quadro apresenta um agravamento expressivo por conta da pandemia. Outro dado preocupante é a chamada flexibilização das leis trabalhistas que prossegue celeremente em meio à crise, ocasionando crescente precarização dos empregos. Não há sinais de recuperação tão cedo.

Algumas iniciativas são apresentadas como alternativas para minimizar a situação. Este é o caso da prefeitura do Rio de Janeiro ${ }^{v}$, que resolveu instalar cinquenta pias públicas no centro da cidade para prevenção do novo coronavírus e designou o espaço do Terreiro do Samba, no complexo do Sambódromo, para ser usado como base de acolhimento e atendimento médico a quem não tem onde dormir e precisa se manter no isolamento. Em São Paulo, epicentro da pandemia, o coordenador da Pastoral Povo da Rua, Pe. Júlio Lancelotti, lançou uma petição ${ }^{\text {vi }}$ para pressionar a prefeitura a fornecer kits com álcool em gel e materiais básicos de higiene e também a abrir espaços públicos para o acolhimento de moradores de rua. O mapa do espraiamento do novo coronavírus que se pode acompanhar pela imprensa mostra as áreas periféricas e empobrecidas da mais rica cidade do Brasil como principais zonas infectadas, o que denuncia os nefastos efeitos do contínuo desinvestimento em políticas públicas e ações sociais de assistência e inclusão.

Mesmo quando se acena com a possibilidade de oferecer ajuda aos menos afortunados, revela-se o flagrante despreparo dos aparatos oficiais. Um exemplo desconcertante é o auxílio emergencial de $\mathrm{R} \$ 600,00$ (seiscentos reais) aos trabalhadores informais, microempreendedores individuais (MEI), autônomos e desempregados como forma de mitigar parcialmente os impactos da pandemia. Financiado pelo Governo Federal com o aumento da dívida pública, tal auxílio emergencial prevê inscrição e acesso on-line por meio de um aplicativo. Antes de comentar sobre a discrepância entre o direito e o acesso às tecnologias digitais de ponta, seria urgente exigir provimento mínimo (comida, água, luz e aluguel) para as famílias de catadores de papel que não possuem vínculo com cooperativas, por exemplo, ou para mães solteiras que trabalham no mercado informal e não possuem cadastro como microempreendedor individual (MEI), bem como outras tantas parcelas excluídas da população.

Se o acesso às plataformas em rede é um fator de discriminação, é preciso considerar também a grande parte da população brasileira que não possui conta em banco ou mesmo aqueles que não têm o cadastro de pessoa física (CPF) ${ }^{\text {vii }}$, exigências para que possam eventualmente receber o auxílio oficial. Todos esses entraves colocam em perspectiva os diversos âmbitos da vida em sociedade: da saúde à educação, da economia à política, do individual ao coletivo. E isso é apenas o começo. A Covid-19 escancarou a precariedade da situação e deu vistas à dramática realidade de desigualdade social que se mantinha à sombra graças à "naturalização histórica das mazelas do País"6.

iv Colosso P. Coronavírus: escancaramento da realidade urbana e saídas possíveis. Carta Capital [Internet]. 2020 abr. 04 [citado em 2020 abr. 21];Blogs. Disponível em: https://bit.ly/2Xqw85I.

v Sabóia G. Rio instalará pias e acolherá morador de rua no complexo do sambódromo. Uol [Internet]. 2020 mar. 21 [citado em 21 abr. 2020];Notícias:Coronavírus. Disponível em: https://bit.ly/3ecQGUL.

vi Prefeitura: forneça acolhida e álcool gel para os moradores de rua se protegem do corona [Internet]. São Paulo: Change.org Brasil; 2020 mar. [citado em 2020 abr. 21]. Disponível em: https://bit.ly/2JXj5Ao.

vii Como pedir o auxílio de R\$ 600? Veja passo a passo. G1 [Internet]. 2020 abr. 07 [citado em 21 abr. 2020 ];Economia. Disponível em: https://g1.globo.com/economia/noticia/2020/04/07/como-pedir-o-auxilio-de-600.ghtml. 
Seguindo a mesma linha da reflexão de Néstor García Canclini sobre a Cidade do México em 2009¹, encaramos as cidades do Rio de Janeiro e São Paulo como laboratórios que nos permitem verificar transformações de toda ordem. Através dessas lentes é possível enxergar o que por vezes parece invisível. Tal qual um vírus, a desigualdade só é detectada quando se sentem seus efeitos e, por essa razão, definições da cidade como 'criativa', 'inteligente' ou 'sustentável' precisam ser colocadas em perspectiva e reinterpretadas.

O projeto de cidade moderna amparado na economia de mercado, na sociedade do consumo e no modelo empresarial de gestão construiu a distância social muito antes de tal distanciamento ser imposto pelas autoridades em função da pandemia. Considerando a cidade como reflexo da vida mental da sociedade 7 , uma crise de tamanha dimensão aponta mudanças nos usos da cidade, nas formas de sociabilidade e nas práticas de gestão do espaço urbano. Essa reflexão ecoa em temas complexos e, por vezes, inconciliáveis tais como meio ambiente e sustentabilidade, que costumam ser tratados como antagônicos ao desenvolvimento e ao progresso. A urbanização, muitas vezes idealizada na forma positiva de progresso, mostrou sua face desordenada como resultado dos interesses políticos e financeiros a ela associados. Neste sentido, quando Lefebvre ${ }^{8}$ defende o direito à cidade, está relacionando o direito do morador urbano às formas de acesso à cidadania. Propomos, então, avançar na ideia de cidadania e no papel central do Estado no atual processo de urbanização, integrando a análise do espaço com as lutas sociais, os processos políticos e a questão ambiental.

\section{CIDADANIA E O PAPEL DO ESTADO}

A ideia de cidadania, como conhecemos, surge em um contexto histórico marcado pelas transformações do poder tradicional, na mudança da sociedade medieval para a era moderna, momento em que se instauram as medidas que constituiriam a nova ordem social destinada a substituir o trabalho servil pelo trabalho livre. Habermas ${ }^{9}$ argumenta que foi a burguesia urbana a grande responsável pela transformação dos súditos em cidadãos. Esta é considerada a grande marca, uma vez que todos os direitos que constituem a cidadania passam por inúmeras modificações com o objetivo maior de regulamentar a inserção do indivíduo na estrutura social. Já Marshall ${ }^{10}$ (p. 79-80) entende a cidadania como um status universal, enriquecida pelos direitos e regulada pelos contratos, uma vez que "o status diferencial associado com classe, função e família foi substituído pelo único status uniforme de cidadania, que ofereceu o fundamento da igualdade sobre a qual a estrutura da desigualdade foi edificada".

É preciso destacar que a ideia do contrato social sempre foi muito cara à implementação da cidadania moderna, especialmente porque os direitos dos homens são uma invenção artificial advinda das suas relações sociais e políticas, uma vez que não nascem iguais, nem livres. Os direitos dos homens e cidadãos constituem uma criação histórica, uma significativa construção social e política realizada a partir de alterações estruturais nas sociedades e quase sempre fruto de lutas e embates sociais contrários às ordens arcaicas. Por outro lado, é sempre necessário reforçar que a constituição do direito, ainda que abrangente, representa uma visão parcial da estrutura social que também não garante a presença efetiva de cidadãos.

Esta perspectiva é importante, principalmente em sociedades como a brasileira com uma excessiva concentração de riquezas e desníveis sociais muito elevados. Dentro desse contexto, a inserção social necessita ser considerada como um ponto de partida básico, muito aquém da estrutura dos contratos sociais e dos ditames legais de toda jurisprudência dos direitos coletivos. O entendimento é de que é papel do Estado para com as coletividades garantir as condições de uma existência digna a todos os indivíduos.

Quando as chamadas periferias do capitalismo encontram seu lugar na metrópole urbana, as crises como a que estamos vivenciando no presente momento revelam a pungente necessidade de investimentos maciços para reabilitar a cidade. O agravamento da crise contrasta com a proclamada incapacidade do poder público de efetivar tais investimentos. O modo de eficiência e gestão concernente às empresas priva- 
das passa a ser a régua pela qual os gestores públicos estabelecem cálculos de custo e benefício acerca dos destinatários desses recursos.

Este tipo de 'socialização capitalista"11 ${ }^{11}$ caracterizada pela transferência de recursos da população como um todo para um grupo reduzido de pessoas e firmas encontra na cidade o meio material e social para o desenvolvimento das forças produtivas e de consumo capitalistas. Ao mesmo tempo, torna o Estado um agente de desigualdade já que favorece concentrações e marginalizações.

Pela seletividade do crédito e demais mecanismos financeiros, a crise atual pode ser entendida como um instrumento de aceleração da socialização capitalista discutida por Milton Santos. A divisão do trabalho e a divisão territorial dependem de decisões políticas e econômicas e respondem, conforme essas determinações, pela reorganização do espaço urbano. Assim, cada parcela do território é valorizada ou desvalorizada em virtude dos jogos de poder vigentes. De um lado, uma fatia majoritária da população se encontra precarizada e desconectada - não somente do acesso aos recursos tecnológicos, mas também desfiliada das instituições de seguridade social em relação a educação, saúde, habitação e trabalho, sobrevivendo muitas vezes abaixo da linha do mínimo. De outro lado, uma minoria conectada e incorporada aos circuitos e instituições de seguridade estaria em condições de escolher. Tal situação de flagrante e lastimável desigualdade representa um grande desafio para o Estado previdenciário.

\section{As 'cidades criativas' e a renda básica universal}

Voltamos nossa atenção para a urgência de retomarmos o debate sobre a renda básica universal e a implementação jurídica da taxa sobre grandes fortunas. Os resultados do amplo estudo de Piketty ${ }^{12}$ sobre o capital no século XXI já apontavam como problemas para o Estado social o acesso à educação, em especial a educação superior, bem como o futuro dos sistemas de pensão em um mundo com baixo crescimento econômico e populacional. Na contramão do que sugerem os especialistas neoliberais, a lei de oferta e demanda e a mobilidade de capital e trabalho não levam a uma maior igualdade de condições. Ao contrário, em uma economia financeirizada e na predominância do trabalho flexível, a maioria dos empresários se tornam rentistas. Seus ganhos projetados pelos agentes financeiros são muito maiores do que qualquer investimento na cadeia produtiva e na geração de emprego e renda.

Considerada a cidade do trabalho com suas construções cinzentas, sua impessoalidade e seu ritmo hiper acelerado e estressante, São Paulo mostra outra face ao figurar entre as denominadas 'cidades criativas'. Trata-se de um esforço por parte dos governantes em destacar o grande número de atrativos culturais nesta megalópole, suas áreas revitalizadas e a diversidade das conexões de suas cadeias produtivas. Nesses termos, o espaço urbano é organizado para comportar os impactos de uma nova ordem econômica de alcance mundial. A chamada economia criativa surge como resposta à desindustrialização global e à desestabilização do modelo fabril de trabalho pela automação. A nova ordem da economia criativa permite que o sistema capitalista continue a se reproduzir.

A 'cidade criativa' passa a ser a condição para a produção de ativos intangíveis, tanto pela via da tecnologia (avanço dos meios de informação e comunicação) quanto pela via da cultura (produção, circulação e consumo de bens culturais no cenário mundial). Em condições precárias e desiguais do território, a criatividade urbana provoca uma sensação de aparente nivelamento das diferenças, mascarando gritantes desníveis sociais. Na verdade, transfere a lógica do Estado para o mercado e exige trabalhadores capazes de estabelecer conexões entre diferentes setores, o que demanda uma adaptação do perfil de capacitação que envolve pensamento flexível, familiaridade com as novas tecnologias e habilidade na tomada de decisões.

Tal modelo de organização urbana seria coerente com o novo paradigma socioeconômico - a passagem da era industrial para a era do conhecimento - e subjaz ao entendimento de uma competitividade econômica entre as diversas regiões. O modelo de gestão do tipo empresarial serve de parâmetro para as deliberações 
políticas do território, onde os serviços mais valorizados passam a ser o turismo e o entretenimento. Tal valorização econômica dos ativos culturais da cidade expõe a incontestável desigualdade de oportunidade e acesso e torna o mundo cada vez mais dividido.

A cidade contemporânea não mais se define como espaço/tempo da produção mercantil (modelo oitocentista), mas como espaço/tempo de reprodução de modelos (produção serializada) de operações funcionais, de signos, mensagens e objetos, de equações racionais, enfim, de simulacros industriais cuja origem é a tecnologia da indústria e cujo referencial é seu próprio discurso que institui como verdade a eficácia, o bom desempenho técnico. Essa redefinição do contexto urbano e social decorre de novas exigências da economia-mundo, vetorizada pelo capital financeiro, pelo controle tecnológico da ordem humana e pela centralidade do marketing como modulador de relações sociais.

A informação e a comunicação, concentradas e aceleradas por dispositivos eletrônicos, se deslocam dos lugares tradicionalmente marcados pela cultura clássica para se converterem prioritariamente em fluxos invisíveis de dados que tornam efetivas as possibilidades de planetarização das finanças. Conforme salienta Rolnik $^{13}$ (p. 373), tem-se um modelo de gestão urbana "organizado sob os imperativos de uma economia neoliberal globalizada, controlada pelo sistema financeiro". Tal modelo "vai penetrando nas cidades e nas políticas urbanas e de moradia, capturando territórios, expulsando e colonizando espaços e formas de viver".

As mutações do trabalho apontam para a precariedade das relações laborais e para o desemprego, mas sempre no âmbito de circuitos de consumo material e simbólico que percorrem transversalmente as classes sociais, indo dos indivíduos mais ricos até os pobres e endividados. Nos novos fluxos financeiros e urbanos, a repressão e o confinamento dão lugar a um ambiente liberatório que acena com a gratificação psicológica e a mística das relações ou dos 'contatos' pessoais mantidos pela rede eletrônica. E com essa nova configuração histórica, a cidade se torna um espaço de atravessamento dos fluxos de consumo em toda a sua complexidade.

\section{Pandemia e a 'cidade inteligente'}

Mas como ficamos quando esses ativos econômicos - as atividades culturais e criativas - implodem com a pandemia? O consumo cultural em lugares públicos dá lugar à cultura em domicílio por meio do acesso ao conteúdo distribuído via internet e à ampla diversidade de canais de rádio e TV. A importância do espaço urbano como lugar do consumo, do trabalho e das formas de sociabilidade se torna ainda maior quando o atual sistema político e econômico é colocado em xeque. Se, por um lado, a crise desfaz os nexos que davam sentido ao mundo tal qual o conhecemos, também nos parece oferecer a oportunidade de estruturarmos outros modos de vivermos juntos na cidade.

Devemos começar pelo projeto de cidade que foi construído até aqui de modo a podermos pensar além dele. Parece inadiável constituir novos modelos de sociabilidade que não se guiem pela competição individual para que possamos encarar o novo tempo vindouro de maneira ética e coletiva. Tal concepção não se basearia nos moldes da 'Utopia' proposta por Thomas More $^{14}$ - uma ilha fictícia na qual se situa o modelo de uma sociedade perfeita baseada em uma nova forma de governo e organização urbana. Parece útil tomarmos a direção de uma 'cidade aberta' descrita por Richard Sennett ${ }^{15}$. Tal modelo de cidade requer que aqueles que nela vivem desenvolvam a capacidade de lidar com crescentes níveis de complexidade.

A tentativa de lidar com uma gestão urbana complexa foi dada pela criação do conceito de 'cidade inteligente', pensada e projetada a partir das inovações trazidas pelo desenvolvimento tecnológico. O Rio de Janeiro tem sido apontado como uma das cidades mais inteligentes e conectadas do Brasil. O Projeto Centro de Operações Rio-COR, quartel-general de dados da prefeitura construído em 2010 em parceria com a IBM, é considerado um case de sucesso e, juntamente com outras iniciativas digitais, estaria transformando a cidade em exemplo de uso da tecnologia para a gestão do território urbano. Em um ambiente cada vez 
mais tecnológico, o analfabetismo digital desponta como mais uma camada na perversa hierarquia das desigualdades sociais.

O ideal de cidade inteligente celebra a marcha inexorável do progresso e da inovação, bastante acelerada pelo engenho e inventividade do setor privado ${ }^{16}$. As abstrações que o termo 'inteligente' sugere fazem emergir tanto visões utópicas quanto sua falta de conexão com problemas reais e pessoas de carne e osso. Na ausência do Estado, as soluções digitais corporativas emergem como sendo voltadas para o bem comum. Entretanto, a pressão pela quantificação do desempenho da cidade engendra uma vasta infraestrutura de coleta, análise e manejo de dados a fim de torná-la mais eficiente, competitiva e administrável. Tal afã de vigilância e controle deixa de fora problemas como a privacidade, a desigualdade e a exclusão social.

Segundo Morozov e $\mathrm{Bria}^{16}$, a entrega do controle das capacidades estatísticas e computacionais para fornecedores privados de serviços pressupõe uma estrada com pedágios: os custos podem ser minimizados e totalmente repassados aos usuários. A relevância na captura e processamento dos dados pessoais e de reputação está na cobrança de preços diferenciados com base na capacidade ou disposição por parte de usuários segmentados em perfis. Desse modo, a cidade inteligente desponta como uma sofisticada forma de controle neoliberal e financista sobre o espaço urbano. Outro aspecto a ser considerado sobre a vasta estrutura de vigilância destinada ao rastreamento constante de recursos físicos e humanos é o enorme precedente que se abre para que outros tipos de experimento, de cunho autoritário, venham a ser colocados em prática com base nesse tipo de controle dos dados em rede.

Mas a tendência por soluções tecnológicas rápidas para a burocracia urbana não pode ser explicada apenas pela fé na tecnologia. Deve ser pensada também com base no fato de que muitas empresas de processamento de dados operam em um sistema de bem-estar social privado e paralelo aos regimes oficiais de governo voltados para setores como a saúde, a educação ou o transporte. Por essa razão é tão difícil encontrarmos um projeto de cidade inteligente que não seja embasado no ideário neoliberal de livre mercado e Estado mínimo.

\section{Vigilância social e estado de exceção - cidade dos meios e cidade dos medos}

A atual pandemia assinala um movimento ainda mais perigoso em relação à vigilância social: o estado de exceção imposto na emergência que vivemos justificaria o avanço do monitoramento e das práticas de extração e processamento de dados privados, sem que tenhamos qualquer controle sobre seus usos e fins. Como observa Sergio Amadeu da Silveira ${ }^{17}$, a tecnologia dos smartphones e da Internet é cibernética. Sendo assim, funciona simultaneamente para comunicação e controle. No entender do estudioso, "a pandemia e a fragilidade da democracia" têm levado as tecnologias cibernéticas a serem utilizadas para um tipo de controle social considerado como exacerbado.

Voltando a nossa atenção para as cidades, tal avanço desordenado da "capacidade de controle dos dispositivos digitais e da modelagem estatística dos algoritmos que extraem padrões e realizam predições" ${ }^{\prime 17}$ pode causar sérias fraturas no espaço urbano, em pelo menos duas frentes. De um lado, seriam excluídos dos mecanismos de cidadania todos aqueles que não tivessem acesso ou habilidade no uso desses dispositivos. De outro lado, os incluídos no sistema de vigilância estariam sob o jugo de uma soberania tecnológica com desenho opaco e altamente autoritário.

O próprio Canclini ${ }^{2}$, em uma reflexão sobre as cidades da América Latina, faz um alerta para a cultura da proteção e da supervigilância, advertindo para novas formas de segregação. Sua principal questão naquele momento concentrava-se na cautela para que a cidade multicultural, característica das megacidades também dos países periféricos, não se convertesse em cidade proibida. Em sua reflexão, o estudioso chamava a atenção para as possibilidades comunicacionais oferecidas pelas então novas tecnologias, assim como também considerava a enorme presença do rádio e da televisão na vida urbana ao destacar seu papel fun- 
damental de formação de imaginários e ordenação da vida quotidiana. Na elegante formulação de Canclini² (p. 71), se "conseguirmos usar criativamente os recursos sociais e comunicacionais poderemos realizar a cidade dos meios e não a cidade dos medos".

Como um exemplo de panorama revigorado na forma eficiente e criativa de comunicação comunitária, a campanha de prevenção sobre o novo vírus em uma comunidade de baixa renda na cidade do Rio de Janeiro ressoou o funk do coletivo Papo Reto nos alto-falantes do Complexo do Alemão:

“Tá ligado no coronavírus? Deixa eu te passar a visão. Essa doença triste que afetou nosso mundão. Vamos ter consciência e fazer toda a prevenção para nossa comunidade. Lave as mãos frequentemente, com água e sabão. Evite sair de casa para não ter aglomeração"viii.

\section{CONSIDERAÇÕES FINAIS}

A 'cidade rebelde' proposta por David Harvey ${ }^{18}$ pode oferecer pistas para um movimento de reconstrução coletiva da cidade sobre as ruínas de uma urbanização capitalista considerada destrutiva. Embora todas as vidas sejam precárias e frágeis diante da pandemia, as desigualdades social e econômica permitem que as vicissitudes do vírus atinjam de modo mais dramático justamente as parcelas da população que sempre estiveram expostas e vulneráveis aos riscos e a toda ordem de privações. Se o desenho urbano molda as maneiras pelas quais nos relacionamos, precisamos alterar esse relacionamento para vislumbrar a construção de um novo modelo de cidade. Isso implica, por exemplo, colocarmos em pauta a questão do meio ambiente.

Ativista do movimento socioambiental e militante em defesa dos direitos indígenas, Ailton Krenak ${ }^{19}$ (p.10) defende que a sustentabilidade é um mito inventado pelas corporações para justificar o assalto que fazem à nossa ideia de natureza: "Fomos alienados desse organismo de que somos parte, a Terra, e passamos a pensar que ele é uma coisa e nós outra: a Terra e a humanidade". Conforme argumenta, a racionalidade moderna transferiu a humanidade para ambientes artificiais produzidos pelas mesmas corporações que hoje devoram os ambientes naturais. E denuncia que a ideia civilizatória que traz à tona o ideal de democracia é a mesma que suprime a diversidade e nega a pluralidade de formas de vida e modos de existência. Desse modo, pensar em desenvolvimento sustentável requer a compreensão sobre o que é preciso sustentar e para quem se destina tal esforço.

Fontenelle ${ }^{20}$ entende o chamado consumo responsável como desdobramento da cultura, principal mercadoria do capitalismo contemporâneo. Conforme argumenta, o consumo responsável desfoca a crítica da produção e coloca a ênfase no ato individual de consumir. Fazendo coro com a sociedade de risco de que nos fala Ulrich Beck ${ }^{21}$, devemos considerar que a imprevisibilidade e magnitude que caracterizam as catástrofes da natureza e as incertezas e medos que elas produzem invisibilizam o avanço histórico da sociedade capitalista e sua distribuição seletiva da riqueza e responsabilizam a sociedade individualmente na distribuição dos riscos. Embora o autor situe a sua discussão a partir de um contexto europeu, o efeito equalizador dos riscos acaba por neutralizar as ações que deveriam contê-los. "Quando tudo se converte em ameaça, de certa forma nada mais é perigoso" ${ }^{21}$ (p. 43). Ao mesmo tempo, os riscos passam a ser fonte de lucro e elementos de manobra política sem, no entanto, serem honestamente confrontados e sem que se assuma a responsabilidade por apurar que tipo de futuro almejamos construir. Devemos estar atentos, pois o medo encapsulado pelo mercado garantidor da segurança individual pode ser transformado em estado de exceção permanente em nome da segurança pública.

viii Criatividade e união ajudam favelas no combate ao novo coronavírus. Correio [Internet]. 2020 mar. 27 [citado em 2020 abr. 21];Variedades. https://correio.rac.com.br/conteudo/2020/03/agencias/917894-criatividade-e-uniao-ajudam-favelas-no-combate-aonovo-coronavirus.html. 
Talvez o único ponto crítico da obra de Beck ${ }^{21}$ seja justamente a hipótese de uma mudança da sociedade de classes para a sociedade de risco. Vivemos no Brasil temporalidades e regionalidades muito distintas. Como vimos, a dependência econômica, a estrutura fragmentada e hierárquica do trabalho e as dinâmicas culturais e sociais na organização dos espaços urbanos deflagram desigualdades abissais nesse país de dimensões continentais. Embora todos estejamos expostos ao risco de contágio do vírus na pandemia, não se pode dizer que as margens de risco são as mesmas por não termos superado a cruel assimetria das classes socioeconômicas no Brasil desigual.

Ao pensarmos nas tantas iniciativas de tornar o futuro previsível por meio de métricas e modelagens informacionais, nos parece que a vida aplica uma rasteira e nos chocamos com o implacável presente. É certo que a pandemia desencadeou uma mudança sem precedentes, mas a crise civilizatória e ambiental já se anunciava para o debate tanto na percepção popular quanto no âmbito da reflexão acadêmica. A aceleração aparentemente descontrolada do progresso estaria dando mostras da sua incapacidade em perpetuar modos de vida baseados em um sistema ultraliberal com pouco apetite para considerações outras que não a crescente maximização dos rendimentos dos mais abastados.

Como argumentam Danowski e Viveiros de Castro $^{22}$, há muito a humanidade parece ter perdido sua parcela de humano para o tecnocapitalismo desterritorializado atual. Resta-nos, como propõe Wisnik ${ }^{23}$, encarar o mundo de dentro do nevoeiro que se impõe no presente. A metáfora concentra tanto a imagem da nuvem de poluição deixada como um rastro indelével da sociedade industrial, quanto a imagem da nuvem de dados que caracteriza em nosso tempo a sociedade informacional.

Talvez o coronavírus desponte como um inquietante e paradoxal agente civilizatório ensejando a emergência de novas formas de sociabilidade e cidadania baseadas na solidariedade e na ação coletiva. Diferentes movimentos sociais e associações de moradores no Rio de Janeiro e em São Paulo articulam ações por conta própria para evitar uma tragédia em áreas com grande densidade populacional, pouca infraestrutura e baixa cobertura de serviços de saúde. Movimento dos Trabalhadores Sem-Teto (MTST) ${ }^{24}$ em São Paulo e da Central Única das Favelas (Cufa) ${ }^{25}$ no Rio de Janeiro são exemplos de lideranças que se organizaram para apoiar, orientar e acolher as famílias em situação de vulnerabilidade. Uma descrição mais pormenorizada das ações sociais desenvolvidas por esses dois importantes movimentos foge ao escopo do presente trabalho. Mencionamos os exemplos para demonstrar como, mesmo inseridas no contexto de brutal desigualdade social, nossas sociedades têm sido capazes de criar mecanismos para compensar, ainda que parcialmente, a falta da presença do Estado e encontrar alternativas para alertar a população a respeito de tão grave problema de saúde pública. A nosso ver, se havia alguma dúvida sobre a possibilidade de existência de organização fora do sistema político-econômico capitalista, tal dúvida parece estar sendo colocada em questão com a pandemia. Para fazer frente às forças de um complexo e sofisticado sistema que cooptou a própria vida e a transformou em mercadoria, outras formas de coletividade e participação política se fazem ainda mais necessárias.

Retomando a ponderação de Canclini $^{1}$ (p. 118) sobre a política como "um campo onde se decide coletivamente os assuntos públicos com vistas a construir um futuro melhor", necessitamos pensar agora como desejamos construir o futuro pós-pandemia. Essa é uma tarefa urgente e inadiável. Ao que tudo indica, não haverá retorno possível ao que era antes. Na articulação lógica entre a instalação de um presente sem perspectiva histórica e o desinteresse pelas disputas travadas no campo político, tanto a racionalidade econômica liberal quanto a autoridade política que moldaram nossa cidadania contemporânea parecem estar irremediavelmente comprometidas.

Para opor resistência à ampliação dos desequilíbrios que caracterizam o projeto atual de modulação mercadológica dos modos de ser e das formas de sociabilidade, precisamos revitalizar o campo político como mobilizador coletivo dos debates de fundo sobre a sociedade na qual queremos viver. Precisamos revitalizar a potência socialmente vinculante da comunicação para a constituição de um revigorado horizonte comum. Por fim, precisamos de novos conceitos para o mundo inexplorado que, certamente, virá. 


\section{REFERÊNCIAS}

1. Canclini NG. Consumo, acesso e sociabilidade. Comum Mídia Consumo. 2009;6(16):111-27.

2. Canclini NG. El dinamismo de la descomposición: megaciudades latinoamericanas. In: Navia P, Zimmerman M. Las ciudades latinoamericanas en el nuevo (des)orden mundial. México, DF: Grupo Editorial Siglo XX; 2004. p. 58-72.

3. Sistema Nacional de Informação sobre Saneamento. Painel de indicadores 2018. Brasília, DF: Ministério do Desenvolvimento Regional; [2018] [citado em 2020 abr. 20]. Disponível em: http://www.snis.gov.br/ painel-informacoes-saneamento-brasil/web/.

4. Ranking de saneamento 2020: 100 maiores cidades brasileira [Internet]. São Paulo: Instituto Trata Brasil; 2020 [citado em 2020 abr. 20]. Disponível em: http://www.tratabrasil.org.br/estudos/estudos-itb/ itb/ranking-do-saneamento-2020.

5. Instituto Brasileiro de Geografia e Estatística. Desemprego, primeiro trimestre de 2020. Brasília, DF: IBGE; [2020] [citado em 2020 mai.28]. Disponível em: https://agenciadenoticias.ibge.gov.br/agencianoticias/2012-agencia-de-noticias/noticias/27821-desemprego-atinge-12-6-no-trimestre-ate-abril-comqueda-recorde-na-ocupacao.

6. Guimarães L. Drauzio Varella prevê 'tragédia nacional' por coronavírus: 'Brasil vai pagar o preço da desigualdade'. BBC News Brasil [Internet]. 2020 [citado em 2020 abr. 20]. Disponível em: https://bbc. in $/ 3 \mathrm{mdB} 5 \mathrm{HT}$.

7. Simmel G. A metrópole e a vida mental. In: Velho OG, organizador. O fenômeno urbano. Rio de Janeiro: Zahar; 1973. p. 11-25.

8. Lefebvre H. O direito à cidade. São Paulo: Centauro; 2001.

9. Habermas J. L'inclusione dell'altro: studi de teoria política. Milão: Feltrinelli; 1998.

10. Marshall TH. Cidadania, classe social e status. Rio de Janeiro: Zahar; 1967.

11. Santos M. Por uma economia política da cidade: o caso de São Paulo. São Paulo: Edusp; 2009.

12. Piketty T. O capital no século XXI. Rio de Janeiro: Intrínseca; 2014.

13. Rolnik R. Guerra dos lugares: a colonização da terra e da moradia na era das finanças. São Paulo: Boitempo; 2019.

14. More T. Utopia. São Paulo: Escrituras; 2003.

15. Sennett R. Construir e habitar: ética para uma cidade aberta. Rio de Janeiro: Record; 2018.

16. Morozov E, Bria F. A cidade inteligente: tecnologias urbanas e democracia. São Paulo: Ubu; 2019.

17. Silveira SA. Capitalismo de vigilância. A terra é redonda [Internet]. 2020 [citado em 2020 abr. 20]. Disponível em: https://aterraeredonda.com.br/capitalismo-de-vigilancia/.

18. Harvey D. Cidades rebeldes: do direito à cidade à revolução urbana. São Paulo: Martins Fontes; 2014.

19. Krenak A. Ideias para adiar o fim do mundo. São Paulo: Cia das Letras; 2019.

20. Fontenelle IA. Cultura do consumo: fundamentos e formas contemporâneas. Rio de Janeiro: Editora FGV; 2017.

21. Beck U. Sociedade de risco: rumo a outra modernidade. São Paulo: Ed. 34; 2011.

22. Danowski D, Viveiros de Castro E. Há mundo por vir? ensaio sobre os medos e os fins. Florianópolis: Cultura e Barbárie; Instituto Socioambiental; 2014.

23. Wisnik G. Dentro do nevoeiro: arquitetura, arte e tecnologia contemporâneas. São Paulo: Ubu; 2018.

24. Movimento dos trabalhadores Sem-Teto [Internet]. Sobre. Disponível em: https://www.facebook.com/ mtstbrasil/ [acesso em 2020 abr. 20]

25. Central Única de Favelas [Internet]. Rio de Janeiro: A Central; 2020 [acesso em 2020 abr. 20]. Disponível em: https://www.cufa.org.br. 